ANUARIO DE Estudios MEDIEVALES

46/1, enero-junio de 2016, pp. 301-328

ISSN 0066-5061

doi:10.3989/aem.2016.46.1.09

\title{
LAS REGENCIAS FEMENINAS \\ EN LOS REINOS IBÉRICOS MEDIEVALES: ¿FUE EL CASO PORTUGUÉS UNA SINGULARIDAD?'
}

\author{
FEMALE REGENCIES IN THE IBERIAN KINGDOMS: \\ WAS THE PORTUGUESE CASE A SINGULARITY?
}

\author{
ANA Maria S. A. RODRIGUES \\ Centro de História da Universidade de Lisboa \\ (UID/HIS/04311/2013)
}

\begin{abstract}
Resumen: Al contrario de lo que sucedió en los otros reinos peninsulares, donde se conocen numerosos ejemplos de ejercicio de la autoridad real por mujeres, en Portugal las dos únicas experiencias de regencia femenina que ocurrieron en la Edad Media fueron interrumpidas por movimientos revolucionarios que entregaron el gobierno a varones de sangre real. En este trabajo, se analizan los argumentos utilizados para retirar el poder a las reinas madres para saber si era su género lo que las descalificaba o si se tenían en cuenta otros motivos más poderosos.
\end{abstract}

Palabras clave: minoría de edad regia; regencia; conciencia nacional; género; populismo.

\begin{abstract}
Quite unlike the situation in other Iberian kingdoms, where several cases of royal authority held by women are known, in Portugal the only two female regencies in the medieval period were abruptly put to an end by revolutionary movements that handed the government over to males of royal blood. This article will analyze the arguments used to remove the queen-mothers from power to understand if it was their gender that disqualified them or if other, stronger, reasons were taken into account.
\end{abstract}

Keywords: royal minority; regency; national conscience; gender; populism.

\section{SUMARIO}

1.- Lopes y Pina, cronistas al servicio de la dinastía de Avis.- 2. Dos regencias legitimadas por la voluntad de los reyes difuntos y un tratado internacional.- 3. El argumento de la amenaza para la independencia nacional.- 4. El argumento de la ineptitud de las mujeres a gobernar.- 5. El argumento del origen popular del poder.- 6. De nuevo el argumento del género.- 7. De nuevo el argumento nacionalista.8. Conclusión.- 9. Bibliografía citada.

\footnotetext{
${ }^{1}$ Abreviaturas utilizadas: ANTT $=$ Arquivo Nacional Torre do Tombo; OA $=$ Ordenações Afonsinas; $\mathrm{PMH}=$ Portugaliae Monumenta Historica. . Hacemos notar que, en este texto, conservaremos los nombres de los personajes en la forma usada en su propio reino para evitar confusiones, porque las homonimias eran frecuentes en la época: João I de Portugal, Juan I de Castilla, Afonso V de Portugal, Alfons V de Aragón, Leonor Teles (y no Téllez), etc.
} 
Los reinos de León, Castilla, Aragón y Navarra conocieron, a lo largo de la Edad Media, numerosas y variadas formas de ejercicio de la autoridad regia por mujeres, incluyendo lugar-tenencias y regencias únicas o compartidas con otros miembros de la familia real $^{2}$. Sin embargo, las dos únicas experiencias de regencia femenina en situación de minoría de edad regia que se dieron en Portugal en ese período ${ }^{3}-$ las de las reinas Leonor Teles de Meneses (1383) y Leonor de Aragón (1438-1439)- fueron interrumpidas de forma abrupta y violenta por movimientos revolucionarios en los que los representantes del pueblo (mejor dicho, de las élites concejiles) se aliaron a una parte de la nobleza y del clero para entregar el poder a varones de sangre real que, en su opinión, eran los únicos aptos para garantizar la independencia del reino y la buena conducción de sus negocios. El género fue un argumento utilizado, en esos momentos, para alejar a las reinas-madres del gobierno efectivo, asociado a otros de distinta naturaleza, como los del origen del poder político o el argumento de la amenaza de una intervención externa.

En la próximas páginas, analizaremos esos argumentos en detalle, a la luz de la coyuntura de la época, intentando determinar si existía algo en la constitución política de la monarquía portuguesa que deslegitimaba a las mujeres como gobernantes, o si fue solamente una correlación de fuerzas desfavorable lo que les perjudicó en su lucha por la conservación del poder. Para hacerlo, utilizaremos todas las fuentes a nuestra disposición; sin embargo, entre ellas se destacan las crónicas de Fernão Lopes y Rui de Pina, por ofrecernos narrativas detalladas pero tendenciosas de los hechos, lo que nos exige algunas consideraciones previas para elucidar a los lectores menos familiarizados con ellas.

\section{LOPES Y PINA, CRONISTAS AL SERVICIO DE LA DINASTÍA DE AVIS}

Fernão Lopes es considerado el mayor cronista portugués. Nacido entre 1380 y 1390, fue nombrado archivero del reino en 1418 y, antes de 1434, el rey Duarte (1433-1438) le encargó escribir las historias de los reyes de Portugal desde el inicio de la monarquía hasta el tiempo de su padre João I (1385$1433)^{4}$. Se discute si las crónicas de los monarcas más antiguos que llegaron a

\footnotetext{
2 Véanse Collins 1993; Echevarría 2002; Carmona Ruiz 2005; Shadis 2009; Earenfight 2010; Biachini 2012, entre otros.

${ }^{3}$ Hubo otras regencias femeninas pero de muy corto plazo y en vida de reyes adultos. De estas no nos ocuparemos.

${ }^{4}$ Marques 1975, p. 56.
} 
nuestros días ${ }^{5}$ son de su autoría, con o sin alteraciones y adiciones posteriores de otros autores ${ }^{6}$. En contrapartida, nadie duda que son suyas las de los reyes Pedro I (1357-1367), Fernando I (1367-1383) y las dos primeras partes de la de João $\mathbf{I}^{7}$; la tercera parte fue escrita por otro cronista, Gomes Eanes de Zurara, que la terminó en $1450^{8}$. Cuatro años más tarde, Lopes fue desplazado del oficio de archivero por ser viejo y débil, datando de 1459 la última referencia documental a su existencia; no se sabe cuándo murió9

La utilización por Fernão Lopes de un amplio abanico de fuentes documentales y cronísticas ya ha sido demostrada por muchos autores, que al mismo tiempo evidencian su probidad ${ }^{10}$. Sin embargo, escritas por encomienda de un monarca que supo utilizar con maestría el arma de la propaganda política en beneficio de su dinastía ${ }^{11}$, las tres crónicas referidas obedecen a una agenda: se trata de legitimar la subida al poder del fundador de esa dinastía, João I, oscureciendo el reinado de su antecesor Fernando I y exaltando el del padre de ambos, Pedro I ${ }^{12}$. En consecuencia, deben ser utilizadas con fuerte espíritu crítico, tanto más cuanto a las esposas de los dos soberanos se les adjudica un papel importante en la construcción de esa narrativa: a Philippa de Lancaster le son atribuidas todas las virtudes y se hace de ella casi una santa ${ }^{13}$; Leonor Teles, en cambio, es presentada como una mujer ambiciosa, adúltera, sin escrúpulos ${ }^{14}$.

En lo que toca a Rui de Pina, nació hacia 1440 y aparece como escribano de la cámara del príncipe heredero cerca de cuarenta años más tarde. Después de subir al trono, João II (1481-1495) le confió varias misiones diplo-

\footnotetext{
${ }^{5}$ Y que se conocieron, en manuscritos distintos, por Crónica de cinco reyes y Crónica de siete reyes, hoy unificados bajo el título de Crónica de Portugal de 1419, Calado 1998.

${ }^{6}$ Lo niegan Marques 1975; Calado 1998, lo afirman Amado 2007; Moreira 2013, entre muchos otros.

${ }^{7}$ Las ediciones que utilizaremos en este texto son: Lopes 1966, 1973, 2004.

${ }^{8}$ Zurara 1992. Se asocia el cambio de cronista al alejamiento del poder y posterior muerte del infante Pedro, protector de Lopes, Monteiro 1988, p. 73. Veremos más adelante que fue este infante quien arrebató la regencia a Leonor de Aragón.

${ }^{9}$ Freire 1973, pp. XXXIII-XXXIV, XLI-XLII.

${ }^{10}$ Russel 1941; Viegas 1985; Caetano 1985b; Monteiro 1988; Amado 1991, entre otros.

${ }^{11}$ Duarte 2007, pp. 292-300.

${ }^{12}$ Que Fernão Lopes difamó deliberadamente Fernando I y Leonor Teles no es una idea reciente: la avanzó hace casi un siglo Alves 1927. Sin embargo, muchos historiadores siguieron (y algunos siguen aún en nuestros días) haciendo una lectura ingenua, literal del cronista y solo paulatinamente su partidarismo se volvió más consensual, Marques 1974,pp. 15-16; Monteiro 1988, pp. 114-117; Coelho 2008, p. 335; Duarte 2002, p. 20; Sousa 2004, p. 93; Gomes 2005 , pp. 127-128.

${ }^{13}$ Hutchinson 2005, pp. 12-13; Silva 2014, pp. 137-149. Estas autoras reconocen, todavía, que Zurara es casi tan importante en la creación del mito de Filipa de Lencastre que Lopes. Véase el artículo de Olivera en este mismo volumen.

${ }_{14}$ Duarte 2002, p. 11; Baleiras 2012, pp. 357-360; Tavares 2013, p. 17.
} 
máticas y además le encargó escribir los hechos famosos del reino y también los del mismo rey ${ }^{15}$. Este encargo y las respectivas rentas le fueron confirmados en 1497 por Manuel I (1495-1521), que también lo hizo archivero y cronista mayor del reino ${ }^{16}$. Fue probablemente entre 1490 y la muerte de João II, en 1495, que Pina escribió la Crónica de Afonso V (1438-1481); en seguida, se dedicó a la del soberano difunto y solo después de 1504 a la de Duarte ${ }^{17}$. Hasta el final de su vida, en 1522, aun escribió las crónicas de otros reyes de Portugal, desde Sancho I (1185-1211) hasta Afonso IV (1325-1357); autores hay, todavía, que sostienen que en este caso se limitó a reelaborar, apropiándoselas, las obras desaparecidas de Fernão Lopes ${ }^{18}$.

Lo mismo que Lopes, Pina fue un burócrata cuya pluma estuvo al servicio de sucesivos monarcas. Tuvo acceso privilegiado a documentos oficiales, pudo hablar con gente que estuvo presente en algunos de los eventos que relató y oír tradiciones orales que circulaban sobre ellos, además de presenciar él mismo otros tantos. Como Lopes, buscó la verdad. Sin embargo, su concepción del papel de la historia, plasmada en los prólogos de las obras que dedicó a Manuel I -suministrar ejemplos de virtudes y de grandes hechos de los hombres del pasado para que pudieran ser replicados por los del presentele llevó a hacer de Duarte un contra-ejemplo de rey indeciso, débil, influenciable y de Leonor de Aragón una manipuladora de la voluntad del marido ${ }^{19}$. En consecuencia, y al igual que los de Lopes, sus testimonios deben utilizarse con muchas precauciones.

Además, el relato de la regencia de Leonor de Aragón fue escrito por Pina entre cincuenta y sesenta y cinco años después de los hechos, ocurridos antes de su nacimiento. En contrapartida, Lopes refiere en la crónica de João I que la estaba escribiendo en $1443^{20}$. O sea, este cronista relató los eventos revolucionarios de 1383, que hicieron huir a Leonor Teles de Lisboa, solo cuatro años después de haber presenciado los que provocaron la destitución de Leonor de Aragón de la regencia en 1439, y la llevaron a alejarse más y más de la corte, hasta exiliarse en Castilla un año más tarde. Es probable que estos le hayan servido (...) de mote inspirador ${ }^{21}$, aunque hay quien sugiere que él también utilizó la memoria oral popular que aún existía en su tiempo

15 Almeida 1977, p. XVI.

16 Ferreira 1975, p. 81.

17 Duarte 2007, pp. 19-20.

18 Almeida 1977, pp. XXI-XXII.

19 Sousa 1984,pp. 420-421.

${ }^{20}$ Freire 1973, pp. XXI-XXII.

${ }^{21}$ Monteiro 1988, p. 117. 
sobre esos sucesos ${ }^{22}$. Por otro lado, es posible que Pina se haya inspirado en la narrativa de Lopes para redactar la suya, ya que los dos momentos tuvieron algunos rasgos comunes. Así, no sería la memoria de los eventos de 1383 la que influiría en los de 1439, sino que, al contrario, los de 1439 servirían de modelo al relato de los de medio siglo atrás. Todo esto lo tendremos que tener en mente a la hora de utilizar las palabras de los dos cronistas. Empecemos, pues, nuestro análisis.

\section{DOS REGENCIAS LEGITIMADAS POR LA VOLUNTAD} DE LOS REYES DIFUNTOS Y UN TRATADO INTERNACIONAL

Delante de los conflictos que siempre ocurrían en caso de sucesión al trono de un niño, algunos reinos se dotaron de leyes estipulando a quién cabía la regencia y fijando la mayoría de edad del rey. En Inglaterra, fue la Magna Carta de 1214 la que estipuló que, en caso de competencia por la regencia, serían la asamblea aristocrática y la de los comunes, o sea, el parlamento, los que tendrían capacidad de decidir ${ }^{23}$. Esto no impidió, sin embargo, los desacuerdos y luchas en torno al nombramiento de los consejos de regencia y la tomada del poder por usurpadore ${ }^{24}$. En Castilla, las Partidas de Alfonso X fijaron la mayoría de edad del rey a su entrada en su décimo cuarto año de edad y determinaron que, en caso de minoría, gobernaría la reina madre -siempre que no volviese a casarse- asistida por un consejo de regencia designado por las cortes ${ }^{25}$. Pero esto tampoco se cumplió en todas ocasiones. Cuando murió Juan I, por ejemplo, la reina madre había fallecido hacía mucho y se la disputaron los partidarios de un consejo de regencia muy amplio salido de las cortes de Madrid de 1391 y los fieles servidores del rey difunto, que exigían el cumplimiento de su testamento; la confusión y las violencias resultantes de esta situación llevaron a que se anticipara la proclamación de la mayoría de edad de Enrique III ${ }^{26}$. El propio Enrique III dejó la tutela de Juan II y la regencia del reino a su mujer Catalina de Lancaster juntamente con el infante Fernando, su hermano, en su testamento, solución ratificada por las cortes de Segovia de $1407^{27}$.

En Portugal, ninguna ley estipulaba cómo se debía proceder en caso de sucesión al trono de un menor de edad. Sin embargo, algunos reyes

${ }^{22}$ Tavares 2013, pp. 9-10.

${ }^{23}$ Corvisier 2002, p. 185.

${ }^{24}$ Wiswall III 1997.

${ }^{25}$ Corvisier 2002, p. 201.

${ }^{26}$ Valdeón Baruque 2002, pp. 77-81.

${ }^{27}$ Echevarría 2002, pp. 101-109. 
habían utilizado sus testamentos para imponer un modelo de regencia: Afonso II (1211-1223) y Sancho II (1223-1248) la confiaron a sus vasallos ${ }^{28}$, asociándoles, el primero, a su esposa Urraca de Castilla ${ }^{29}$. También en su testamento, del 28 de agosto de 1378, Fernando I hizo de Leonor Teles la tutora de su única hija Beatriz y la regente del reino hasta que la niña consumara su matrimonio con el duque de Benavente -su prometido en esa época- $\mathrm{o}$ alcanzara los 12 años de edad ${ }^{30}$. Aunque estas disposiciones fueron alteradas por el tratado de Salvaterra de Magos, de 2 de abril de 1383, que regulaba no sólo las condiciones del matrimonio de la infanta Beatriz de Portugal con su nuevo prometido, el rey Juan I de Castilla, sino también las de la sucesión a los dos tronos. La infanta sólo sería la sucesora de su padre si, a la muerte de éste, no quedaba ningún hijo varón legítimo, nacido o por nacer, ni ningún sucesor legítimo de éste. En caso que Beatriz muriera sin herederos legítimos, su marido sería rey de Portugal. Inversamente, si Juan I y su hermana Leonor muriesen sin descendencia, Fernando I heredaría el trono de Castilla. Para que el gobierno de los dos reinos permaneciera separado, sería Leonor Teles quien debía asegurar la regencia en nombre de Beatriz hasta que un hijo o hija de esta y de Juan I llegara a la edad de catorce años. La reina madre también educaría al heredero del trono de Portugal y a sus eventuales hermanos en suelo portugués a partir de los tres meses de edad. Los poderes de Leonor como regente serían muy amplios: administración de la justicia; gestión de los bienes, derechos y rentas reales; nombramiento de los oficiales respectivos; designación y destitución de alcaides y recepción de homenajes; acuñación de la moneda; convocatoria de cortes; derecho de patronazgo sobre las instituciones religiosas ${ }^{31}$.

Visto desde el presente, porque sabemos lo que sucedió, el tratado parece ser demasiado desigual. Juan I y Leonor de Castilla tenían varios hijos varones, Fernando I sólo una hembra y además padecía desde hace tiempo de una enfermedad que acabaría por matarle unos meses más tarde ${ }^{32}$. Pero que su muerte ocurriría a muy corto plazo, él no lo sabía. Lo que sí sabía, era que la reina estaba embarazada y aún podía darle un hijo. Tal felicidad casi había ocurrido en julio del año anterior, cuando Leonor Teles había alumbrado a un niño que murió pocos días después. Desgraciadamente, en septiembre de 1383 nació una niña que tampoco sobrevivió mucho tiempo ${ }^{33}$. Y Beatriz, cuyo

${ }^{28}$ Albuquerque 1973,pp. 204-205.

29 Marques 2013,p. 89.

${ }^{30}$ Baleiras 2012, pp. 166-167.

31 Arnaut 1960, doc. 26, pp. 357-393.

${ }^{32}$ La enfermedad del rey ha sido discutida por los historiadores, que durante mucho tiempo se inclinaron hacia la tuberculosis pulmonar; hoy en día, se piensa que su muerte resultó de las secuelas de un envenenamiento acaecido algunos años antes, Gomes 2005, pp. 159-166.

${ }^{33}$ Baleiras 2012, pp. 226, 256. 
matrimonio con Juan I ya se había consumado a pesar de tener poco más de diez años de edad ${ }^{34}$, permaneció como sola heredera de su padre cuando este falleció el 22 de octubre siguiente.

En el caso de Leonor de Aragón, fue el testamento de su marido Duarte el que le confió la tutela de sus hijos y la regencia del reino in solido. Lo sabemos porque lo dice el cronista Rui de Pina; el documento mismo desapareció, al igual que todas las copias que la reina ordenó se hicieran entonces por su guarda ${ }^{35}$. El hecho de que legitimara, sin ninguna ambigüedad, el ejercicio de la autoridad regia por la reina viuda en exclusividad, cosa que le fue muy pronto retirada y ella no cesó de reivindicar hasta su muerte, dictó probablemente la destrucción de este instrumento de últimas voluntades por sus rivales ${ }^{36}$.

Según relatan las crónicas, las dos Leonores comenzaron a gobernar poco después de la muerte de sus maridos sin oposición declarada: nadie, en los círculos próximos del trono, contestó públicamente su legitimidad como regentes ${ }^{37}$. Sin embargo, se detecta una diferencia señalada en las circunstancias del alzamiento de los dos herederos al trono: el de Afonso V, el niño de seis años y medio que sucedió a Duarte, efectuado el día siguiente al de la muerte de su padre, no suscitó ninguna conmoción ${ }^{38}$. El de Beatriz, por el contrario, se reveló problemático; los relatos de los cronistas sobre él, sin embargo, no coinciden y nos despiertan muchas dudas.

Fernão Lopes dice que fue Juan I de Castilla que, sabiendo de la muerte de su suegro, envió cartas a Leonor Teles y a algunos alcaides del reino vecino para que hiciesen aclamar a su esposa Beatriz como reina de Portugal. La regente procedió a la ceremonia de inmediato y ordenó a aquellos de los referidos alcaides que no se atrevieron a actuar sin pedirle primero su aprobación que lo hiciesen también ${ }^{39}$. En compensación, Pero López de Ayala no se refiere a estas supuestas cartas del rey castellano, pero sí a las que grandes omes del Regno de Portugal le enviaron para que fuese a tomar el reino que pertenecía a su mujer. Podríamos pensar que, al igual que Lopes, Ayala está intentando justificar acontecimientos futuros, en particular la entrada de Juan I,

${ }^{34}$ El legado papal Pedro de Luna la había declarado, para el efecto, "ser muy próxima et muy llegada a pubertad et ser tan corpulenta et tan discreta et jndustriosa et de tan buen entendimjento et de tamaño vigor natural et assi poderosa para ser con ella consumado matrimonio", Arnaut 1960, doc. 29, p. 402.

${ }_{35}$ Pina 1977, cap. III, p. 591. Esta y las otras traducciones al castellano son de nuestra responsabilidad.

${ }^{36}$ Duarte 2007, p. 359.

${ }^{37}$ Lopes 2004, cap. CLXXIII, p. 593; Pina 1977, cap. III, p. 590.

${ }^{38}$ Pina 1977, cap. II, pp. 588-590.

${ }^{39}$ Lopes 2004, cap. CLXXV, p. 601. 
armado, en Portugal. Pero el cronista castellano, en este como en otros capítulos de su crónica, da también voz a los que, en el concejo regio, desaprobaban las medidas tomadas por el monarca (tomar voz y armas de Portugal, llamar a hombres de armas para entrar en el reino vecino, etc.) porque consideraban que iban en contra a los compromisos del tratado de Salvaterra de Magos, minando la legitimidad de su esposa y la suya ${ }^{40}$.

Los dos cronistas están, sin embargo, de acuerdo en que Juan I de Castilla envió otras cartas a la regente, los grandes de Portugal y a algunas villas y ciudades del reino, para que tomasen a Beatriz como su reina y a él como su rey en virtud de los pactos establecidos entre los dos reinos. Ayala refiere que Alfonso López de Tejada, el emisario del soberano, llegó a Lisboa con estas cartas cuando se celebraban los setenta días de la muerte de Fernando I; sólo entonces habría ordenado la regente el alzamiento y aclamación de su hija ${ }^{41}$. Lopes, en contrapartida, hace coincidir la llegada del mismo emisario con las exequias del soberano portugués, a los treinta días de su muerte ${ }^{42}$. Así ¿cuándo, y a mando de quién, tuvo lugar el alzamiento de Beatriz?

Bajo la dinastía de Avis, la proclamación de un nuevo rey de Portugal empezó a hacerse al tercer día después de la defunción de su antecesor ${ }^{43}$; con Afonso V, en cambio, se anticipó la ceremonia a causa de la situación de minoría de edad del rey. En el caso de la reina Beatriz, se sostiene que la aclamación tuvo lugar, sea en Toledo, después de las exequias solemnes por su padre mandadas celebrar por Juan $\mathrm{I}^{44}$, sea en Lisboa y otros lugares del reino, después de que la regente hubiera recibido una carta de su yerno ordenándole que así lo hiciera ${ }^{45}$; en ambos casos, tardíamente y por iniciativa del rey de Castilla, lo que no nos parece verosímil. Sobre todo, porque a Leonor Teles, cuya legitimidad como regente derivaba de que su hija fuera reconocida como reina propietaria de Portugal, no le interesaba que se instalara un tiempo en que no hubiera rey, un interregno ${ }^{46}$, durante el cual la oposición a su poder, que ya había sido grande durante el reinado de su marido, podría expresarse aún más libremente. Creemos, por eso, que la regente hizo aclamar a su hija en

\footnotetext{
40 Ayala 1877, caps. VII-X de 1383, pp. 83-85.

${ }^{41}$ Ibidem, cap. XII de 1383, p. 86. La inconsistencia cronológica del relato de Ayala ya ha sido puesta en relieve por Amado 1991, pp. 186-188.

${ }^{42}$ Lopes 2004, cap. CLXXVIII, pp. 611-612.

${ }^{43}$ Carvalho-Gonçalves 2014, p. 189.

${ }^{44}$ Gomes 1995, p. 304.

${ }^{45}$ Baleiras 2012, pp. 273-275; Tavares 2013, pp. 427-428.

${ }^{46}$ Este es el término que algunos historiadores portugueses utilizan para clasificar el tiempo que medió entre la muerte de Fernando I y la elección de João I en las cortes de Coímbra, deslegitimando la regencia de Leonor Teles y el reinado de Beatriz. Pocos son los que reconocen a esta y a su marido como reyes legítimos de Portugal, como Sousa 1993, p. 494.
} 
Lisboa, por su propia iniciativa, poco tiempo después de la muerte de su marido, como era costumbre, y que Lopes le atribuyó a Juan I el protagonismo para poder presentar a Leonor en su crónica como un instrumento al servicio del monarca castellano, justificando las reacciones adversas verificadas.

En efecto, el grito de Real, real, real... por Beatriz fue recibido con hostilidad en muchos lugares, donde la gente no quería aclamar como su reina propietaria a la reina de Castilla, pero sí aclamar como rey al infante João de Castro, hermanastro de Fernando I por ser hijo mayor del rey Pedro I y de Inés de Castro $^{47}$. A pesar de que Beatriz hubiera sido jurada heredera del trono en las cortes de Leiria de $1376^{48}$ y el tratado de Salvaterra de Magos hubiera igualmente sido jurado por los más grandes señores portugueses ${ }^{49}$ después de la celebración de su boda con Juan I, confiriéndole plena legitimidad para reinar, el pueblo e incluso algunos de esos señores preferían un varón de sangre real explícitamente excluido de la sucesión por el rey difunto en su testamento ${ }^{50}$ pero que no ponía en peligro la independencia nacional.

\section{EL ARGUMENTO DE LA AMENAZA PARA LA INDEPENDENCIA NACIONAL}

En sus dos crónicas, Fernão Lopes hace del sentimiento nacional uno de los fundamentos principales del rechazo hacia la regente y a su hija. Siguiéndole, muchos historiadores han considerado la crisis o revolución ${ }^{51}$ de 1383-1385 como un momento crucial en la formación de la conciencia nacional portuguesa ${ }^{52}$. Sin embargo, podemos dudar de la existencia de un tal sentimiento en algunos de los estamentos sociales del tiempo. Tal como el restante clero europeo, el clero portugués dependía de una autoridad extranjera, el papado, y tenía una dimensión transnacional, pudiendo ambicionar un beneficio en cualquier iglesia de la Cristiandad; pero ha sido comprobado que eran mucho más numerosos los franceses y castellanos que obtenían canonjías y obispados en Portugal que los portugueses que conseguían expatriarse ${ }^{53}$, lo

47 Lopes 2004, caps. CLXXV-CLXXVII, pp. 601-610.

${ }^{48}$ Estas cortes se habían reunido únicamente para aprobar el matrimonio de la infanta con Fadrique, hijo bastardo de Enrique II de Castilla, y jurarla heredera del trono portugués, Marques 1990, p. 149.

49 Entre los cuales figuraba el maestre de Avis, Arnaut 1960, doc. 26, pp. 384-387.

${ }^{50}$ Fernando I argumentara que, a pesar de lo declarado por su padre, los infantes João, Dinis y Beatriz no habían nacido de legítimo matrimonio y por eso no podían heredar el trono de Portugal, Arnaut 1960, doc. 7, p. 294.

${ }^{51}$ Utilizamos los dos términos en cursiva porque no pretendemos tomar posición ni adentrarnos en el debate sobre la caracterización de este período, que nos alejaría demasiado del tema que tratamos.

52 Albuquerque 1974, pp. 78-82; Mattoso 1985b, pp. 60-62; Godinho 2004, pp. 45-53.

${ }^{53}$ Rodrigues, Vilar 2003, p. 152. 
que suscitaba envidias y conflictos que explican en parte su acrimonia hacia los extranjeros. Por otro lado, el Cisma que dividió la Iglesia a partir de 1378 también dividió al clero portugués ${ }^{54}$, y si Fernando I cambió dos veces de obediencia durante su reinado, provocando una enorme confusión, el maestre de Avis permaneció adepto al papa de Roma. De esta forma, los clementistas portugueses se aliaron a los castellanos y, acusados de traidores y cismáticos, fueron forzados a exiliarse tras su derrota, mientras que los urbanistas eran considerados los verdaderos portugueses ${ }^{55}$.

En lo que toca a la nobleza ibérica, era frecuente ver a sus miembros cruzar las fronteras nacionales e incluso ponerse al servicio de monarcas extranjeros cuando suscitaban la ira de sus señores naturales. Durante su reinado, Fernando I estuvo rodeado de castellanos y gallegos, partidarios de Pedro I el Cruel, que lo propusieron como heredero del trono después del asesinato de su soberano en 1369 e incentivaron las tres guerras que él tuvo con Castilla ${ }^{56}$. En sentido contrario, el infante portugués Dinis de Castro se juntó a Enrique II cuando éste invadió Portugal, en 1373, al parecer por no haber aceptado el matrimonio de su hermanastro Fernando I con Leonor Teles ${ }^{57}$. Los hidalgos João Lourenço da Cunha -el primer marido de Leonor- y Diogo Lopes Pacheco perdieron sus bienes en 1379 y 1380 por haber participado en la misma invasión y, más tarde, haber intentado envenenar al rey ${ }^{58}$. El infante João de Castro, hermano de Dinis, también se exilió en Castilla, en 1380, como consecuencia de haber asesinado a su esposa Maria Teles, hermana de la reina Leonor $^{59}$. Otros nobles cambiaron de campo en distintos momentos de la regencia de Leonor Teles y de la del maestre de Avis, incluso más de una vez ${ }^{60}$.

Si al clero y a la nobleza portugueses no les movía el sentimiento nacional, ¿qué decir de la burguesía y del pueblo? La primera audiencia concedida por Leonor Teles después de la muerte de su esposo tuvo como protagonistas a los hombres buenos de la ciudad de Lisboa, que le pidieron, entre otras cosas, que dejara de tener en su consejo a castellanos y gallegos, y que escogiera para remplazarles a prelados naturales del reino, juntándoles dos ciudadanos de cada comarca. En efecto, esos burgueses atribuían los males

${ }^{54}$ Batista 1956; Costa 1982.

${ }^{55}$ Marques 1989; Olivera Serrano 2005, pp. 234-240.

${ }^{56}$ Mattoso 1985a, pp. 392-393; Gomes 2005, pp. 69-74.

${ }^{57}$ Tavares 2013, pp. 239-240.

${ }^{58}$ Tavares 1983, p. 56.

${ }^{59}$ Según Fernão Lopes, esto resultó de un plan diabólico urdido por Leonor Teles, que hizo el infante pensar que podría casarse con su sobrina Beatriz si mataba a su esposa, acusada de adulterio, y luego le retiró su apoyo, Lopes 2004, caps. CI-CVI, pp. 361-384. Recientemente ha sido propuesta una nueva explicación para este asesinato, Tavares 2013, pp. 348-358.

${ }^{60}$ Tavares 1983, pp. 73-82; Mattoso 1985a, pp. 396-400. 
que se habían abatido sobre el reino a los extranjeros que habían convencido al monarca difunto para hacer la guerra al reino vecino y querían evitar que lo mismo se pasase con la regente. Leonor aceptó ${ }^{61}$. Sin embargo, siguió aconsejándose con los mismos validos, entre los cuales se destacaba el gallego Juan Fernández Andeiro.

Otra de las quejas presentadas en esa primera audiencia a la regente por los ciudadanos de Lisboa fue en contra de los judíos y moros que ejercían oficios reales y cobraban las rentas regias, oprimiendo a los cristianos. Si en el caso de los consejeros extranjeros el argumento de la naturalidad servía, en realidad, para disfrazar una rivalidad política, aquí el argumento de la religión ocultaba a la competencia económica. De la misma manera, Leonor contestó que ya había despedido a todos los oficiales judíos y no les permitiría cobrar más sus rentas, a pesar de reconocer que le daban más por ellas que los de su propia fe. Algunos meses más tarde, sin embargo, cuando huyó de Lisboa a su villa de Alenquer, entre los fieles que le siguieron se contaban Judas Aben Menir y David Negro ${ }^{62}$. En ambos los casos, la regente prometió una cosa pero hizo otra, lo que acabó teniendo consecuencias nefastas para sus partidarios ${ }^{63}$.

Juan Fernández Andeiro era un petrista que, después del fratricidio de 1369, se había refugiado en Portugal y luego en Inglaterra, en la corte del duque de Lancaster, cuyos intereses representaría en las alianzas hechas con Portugal en 1372 y $1373^{64}$. En mayo de 1380, volvió a Portugal para iniciar nuevas negociaciones y fue a partir de ese momento cuando se estableció, según dice Lopes, su relación adúltera con la reina, glosada en muchos pasos de la crónica de Fernando I: fue por influencia de Leonor que el rey le atribuyó el título de conde de Ourém y, para muchos cortesanos, los dos hijos que la reina parió en 1382 y 1383 le tuvieron a él como progenitor, no al soberano ${ }^{65}$. En los primeros capítulos de la crónica de João I, Fernão Lopes sigue discurriendo sobre la supuesta infidelidad de la reina. João Afonso Telo IV, hermano de Leonor, y otros nobles portugueses, indignados con el hecho de que el conde de Ourém traicionara al rey durmiendo con su esposa, planearon matarle; el mismo Fernando I lo quiso hacer pero se arrepintió y al final, por uno u otro motivo, la intención no llegó a concretarse durante la vida del rey ${ }^{66}$. Sin embargo, después de su muerte el tema no cayó en el olvido: los vasallos

${ }^{61}$ Lopes 2004, caps. CLXXIII-CLXIV, pp. 593-600.

${ }_{62}$ Tavares 2013, p. 436.

${ }_{63}$ En lo que toca a los judíos, hubo una tentativa de ataque a la judería por parte del pueblo de Lisboa y sólo el maestre de Avis consiguió impedirlo, Lopes 1973, cap. XIV, pp. 29-30.

${ }^{64}$ Russel 1938,pp. 5-10.

${ }^{65}$ Lopes 2004, caps. LXV, p. 229, CL, pp. 523-524, CLXXII, p. 591.

${ }^{66}$ Lopes 1973, caps. I-IV, pp. 3-9. 
del difunto siguieron discutiéndolo y Andeiro acabará siendo asesinado a inicios de diciembre de 1383 .

El adulterio de Leonor Teles con Juan Fernández Andeiro fue, durante mucho tiempo, un hecho incontestado para la mayoría de los historiadores portugueses ${ }^{67}$. Solo recientemente se empezó a poner en duda la versión de Fernão Lopes, contraponiéndole el silencio absoluto de otros cronistas -entre los cuales Pero López de Ayala, contemporáneo de los hechos- sobre el asunto ${ }^{68}$ o dando a la acusación de adulterio otro sentido ${ }^{69}$. En nuestra opinión, saber si Leonor y Juan fueron o no amantes, antes o después de la muerte de Fernando I, importa poco. Lo que sí nos parece importante, es que la acusación de infidelidad fue un arma que sirvió, durante la Edad Media, para descalificar a los reyes que se dejaban dominar y traicionar por sus esposas y para deslegitimar a su progenie ${ }^{70}$. En este caso, además de contribuir a oscurecer un poco más la imagen de la reina, sirvió también para justificar el asesinato de su supuesto amante. Un asesinato que, más que en las cuestiones de honor de linaje referidas por el cronista, tiene sus raíces en la lucha por el poder que se desencadenó en torno a la regencia.

En efecto, lo que estaba en juego en Portugal en fines de 1383 era la proximidad a la regente, la posibilidad de influenciarla o incluso de compartir con ella el poder. Leonor Teles había prometido alejarse de los nobles extranjeros y gobernar con prelados, nobles y hombres buenos portugueses; sin embargo, era con Juan Fernández Andeiro que, según el cronista, trataba de todos los asuntos del reino ${ }^{71}$, causando la envidia de los demás miembros de su consejo, que querían eliminarle. Lo que acabó convenciendo a João, hermanastro del rey difunto y maestre del orden de Avis, de llevar a cabo un acto tan arriesgado fue el apoyo popular prometido por Álvaro Pais, un antiguo veedor de la cancillería ${ }^{72}$ influyente entre los oficiales superiores de la monarquía y en el concejo de Lisboa. Según el relato casi cinematográfico de Fernão Lopes, al mismo tiempo que el maestre de Avis mataba a Andeiro, un paje cabalgaba por las calles de Lisboa gritando que lo mataban a él y sus partidarios corrían a socorrerle, juntándose una enorme multitud de gente armada delante del palacio real. Esa multitud hubiera entrado y matado a la regente si él se lo ordenara, pero João dijo a los presentes que ya no los necesitaba y todos se

\footnotetext{
${ }^{67}$ Lo sigue siendo para quién sigue el cronista Fernão Lopes, como Moreno 2009; Oliveira 2010.

${ }_{68}^{6}$ Duarte 2002, pp. 61-67; Baleiras 2012,p. 376.

${ }^{69}$ ¿Existiría acaso una tradición de considerar adúltera a Leonor por haber sido casada con João Lourenço da Cunha antes de casarse con el rey?, Tavares 2013, p. 10.

${ }^{70}$ Gomes 2005, pp. 128-129.

${ }^{71}$ Lopes 1973, cap. VII, p. 14.

${ }^{72}$ Y no canciller, como dice Fernão Lopes, Homem 1990, pp. 281-282.
} 
fueron ${ }^{73}$. Algunos días más tarde, el maestre de Avis, aconsejado por Álvaro Pais, aún intentó acercarse al poder dentro de la legitimidad vigente pidiendo perdón a la reina por el asesinato y proponiéndole matrimonio, pero Leonor Teles rechazó tal solución y la ruptura entre los dos quedó consumada ${ }^{74}$.

\section{EL ARGUMENTO DE LA INEPTITUD DE LAS MUJERES A GOBERNAR}

Con Leonor de Aragón, las tentativas para hacerle compartir el poder con un hermano del rey difunto también empezaron muy pronto. Como dijimos anteriormente, Rui de Pina sostiene que la regente empezó a gobernar a solas sin oposición abierta; en efecto, su primer acto en esa condición data del 24 de Septiembre de 1438, pasados apenas quince días de la muerte de su esposo $^{75}$. Sin embargo, Zurara afirma que el hecho de que Duarte dejara el gobierno del reino a la reina viuda pareció casi a todos contrario a la buena razón $n^{76}$ y el mismo Pina pone en la boca de los consejeros de Leonor los argumentos que debían esgrimir sus opositores:

porque Vuestra Señoría ha de considerar que son en este reino tres infantes, grandes príncipes y de gran autoridad, y naturales de la tierra que han de estimar por gran quiebra y abatimiento de sus estados ser regidos por una mujer, especialmente no natural ni heredera, como vos sois ${ }^{77}$.

Los tres infantes a los que se refería el cronista eran Pedro, Henrique y João, los hermanos del rey difunto. Pedro, el mayor, era duque de Coímbra, Henrique, duque de Viseu y maestre de la orden militar de Cristo y João, maestre de la de Santiago. Todos habían tenido una presencia de relieve en la corte de su padre y de su hermano, prodigándoles consejos y ratificando sus decisiones ${ }^{78}$. En realidad, existía un cuarto hermano, Fernando, pero este se había quedado como rehén en Marruecos el año anterior, en resultado de la fracasada tentativa de conquista de Tánger, y por eso no podía tener ningún rol activo en el reino; acabó muriendo en la prisión en $1443^{79}$.

${ }^{73}$ Lopes 1973, caps. V-XI, pp. 10-23.

${ }^{74}$ Ibidem, caps. XIII, XXV, pp. 26-29, 43-45.

75 ANTT, Chancelaria de D. Afonso V, L. 18, fl. 71, referido por Moreno 1979, p. 8.

76 Zurara 1978, cap. XXV, p. 109.

77 Pina 1977, cap. III, p. 591. En realidad, el cronista pone casi las mismas palabras en la boca del infante Juan en una charla con su hermano Pedro, algún tiempo más tarde: "nunca he visto tal vergüenza y abatimiento nuestro que ser regidos por ella; porque es mujer, y además extranjera". Ibidem, cap. XXII, p. 609.

${ }_{78}$ Sobre ellos, véanse Moreno 1997; Medeiros 1999; Russel 2004; Costa 2009.

79 Sobre él, véase Fontes 2000. 
Para Rui de Pina, como para muchos otros autores medievales, el simple hecho de ser mujer descalificaba Leonor como regente delante de sus cuñados, varones con pruebas dadas en el gobierno de sus señoríos y maestrazgos, y en la asesoría de los reyes anteriores. En otros pasos de su crónica, Pina explica el porqué: por su naturaleza, la mujer es ligera, inconstante, voluble, débil; la falta de firmeza de sus decisiones genera enemistades y conflictos. Por ejemplo, para obtener el apoyo del infante Pedro, Leonor de Aragón propuso casar a su hijo, el rey, con la hija mayor de él, Isabel; pero como hubo oposición por parte de sus partidarios, retiró la propuesta. En otro momento, también acordó con Pedro compartir con él el regimiento y volvió hacia atrás en su decisión ${ }^{80}$. Todo esto suscitó la creciente desafección del infante. Por otro lado, pertenece a la naturaleza de la mujer quedarse embarazada, y el estado de buena esperanza no es conciliable con el regimiento. A pesar de sus buenas intenciones y propósitos, dice Pina, Leonor, embarazada cuando su marido falleció, tuvo pronto que reducir su actividad para aliviar los dolores y enfermedades que su estado le causaba, y los requerimientos empezaron a acumularse, causando murmuraciones y reclamaciones entre los peticiona$\operatorname{rios}^{81}$.

\section{EL ARGUMENTO DEL ORIGEN POPULAR DEL PODER}

El género no era, sin embargo, el único ni siquiera el más importante argumento utilizado en contra de la regente. En las cortes de Torres Novas, reunidas en noviembre de 1438 para que los tres estados del reino prestaran pleito homenaje a Afonso $\mathrm{V}$, se discutió la cuestión del regimiento. A pesar de que se leyó públicamente el testamento en que Duarte dejaba la regencia solo a su mujer, fueron expresadas opiniones divergentes sobre la titularidad del regimiento, revelando la existencia de varios partidos. Uno de ellos, representado por los procuradores del concejo de Lisboa, sostuvo delante del rey niño que:

El Rey, vuestro padre, no podía hacer tal testamento; ni en tal caso dejar Regidor del Reino a su disposición; porque a nosotros, vuestro pueblo, pertenece por derecho elegir a quién, por defecto de vuestra madura edad, nos haya por Vos de defender con las Armas, y regir por Leyes con justicia (...) porque así como a nosotros solamente pertenece elegir el Rey, si la Real, y legitima sucesión de los Reyes de estos Reinos por algún caso, que Dios no lo quiera, se extinguiera, y no se guardaría en tal caso el

${ }^{80}$ Pina 1977, caps. VI-VIII, pp. 594-596, caps. XII-XIII, pp. 599-600.

${ }^{81}$ Ibidem, cap. XIX, p. 607. 
Testamento, ni disposición del Rey postrimero; así pertenece a nosotros elegir ahora un Regidor por $\operatorname{vos}^{82}$.

Este argumento del derecho del pueblo a elegir a un regidor en caso de minoría de edad regia, y al rey en caso de quedar el trono vacante, remite a los acontecimientos revolucionarios de 1383-1385. Tras la muerte del conde Andeiro, Leonor Teles no se sentía segura en Lisboa, tanto más cuanto que los revoltosos habían asesinado también a otro de sus partidarios, el obispo de Lisboa, un castellano; en consecuencia, se trasladó con su corte a una villa de su señorío, Alenquer. El pueblo menudo de Lisboa aprovechó su ausencia para elegir al maestre de Avis regidor y defensor del reino en un acto espontáneo que fue después ratificado por los hombres buenos del concejo, el 16 de diciembre de $1383^{83}$. Eso dio a João legitimidad suficiente para instituir un gobierno paralelo al de la regente y preparar la resistencia al invasor castellano, pues Juan I había entrado armado en Portugal unos días antes ${ }^{84}$.

$\mathrm{Al}$ tener conocimiento de esto, Leonor Teles escribió a su yerno pidiéndole que la ayudara a castigar a los rebeldes, pero cuando se encontró con él en Santarém el 12 de enero de 1384, el monarca castellano la convenció -o la forzó- a renunciar a la regencia. En consecuencia, muchos nobles portugueses que se habían mantenido fieles a la regente y a la reina Beatriz consideraron que se había roto el tratado de Salvaterra de Magos y las dejaron. La propia Leonor acabó arrepintiéndose de lo que había hecho e ingenió un plano para matar a su yerno y recuperar la regencia. Juan I lo descubrió y la envió, presa, al monasterio de Santa Clara de Tordesillas ${ }^{85}$; jamás regresó a Portugal. En seguida, el rey de Castilla se dispuso a conquistar las ciudades y villas que se le resistían, en especial Lisboa, a la que puso cerco a partir de fines de mayo. Sin embargo, el fracaso del cerco y la retirada de Juan I hacia Castilla en septiembre siguiente llevó los hombres buenos de la capital a prestar a João nuevo pleito homenaje como regidor y defensor del reino, acompañados esta vez por numerosos nobles que habían participado en la defensa de la

82 Ibidem, cap. XIV, p. 601.

${ }^{83}$ Lopes 1973, caps. XVI-XXVI, pp. 32-48. La fecha la propone Caetano 1985a, p. 125.

${ }^{84}$ Los relatos divergen sobre los responsables de esa entrada. Lopes la atribuye a la regente, que como consecuencia del asesinato de Andeiro habría escrito a su yerno pidiéndole "que se trabajara de venir deprisa al reino", Lopes 1973, cap. XLII, p. 72. Ayala, como ya decimos, sostiene que fueron los nobles portugueses, entre los cuales se refiere explícitamente el maestre de Avis, quienes apenas muerto Fernando I invitaron a Juan I a "ir á tomar el Regno de Portogal, que pertenescia de derecho á la Reyna Doña Beatriz, su mujer", Ayala 1877, año quinto (1383), cap. VII, p. 83. Fuese como fuese, el rey de Castilla entró en Portugal por la ciudad de Guarda el 13 de diciembre de 1383, Arnaut 1960, p. 175.

${ }^{85}$ Baleiras 2012, pp. 301-316. 
ciudad, lo que reforzó su autoridad ${ }^{86}$. El título de rey, sin embargo, sólo le fue concedido en las cortes que se reunieron en Coímbra en marzo y abril de 1385.

En esa ocasión, el objetivo de los discursos hechos por el doctor João das Regras ${ }^{87}$, un jurista partidario del maestre de Avis, fue probar que ni Beatriz de Portugal ni João de Castro ni Dinis de Castro eran hijos legítimos y herederos posibles del reino de Portugal: Beatriz porque su madre había estado casada con otro hombre antes de casarse con Fernando I, y ese primer matrimonio no había sido disuelto por razón válida; João y Dinis porque su madre Inés de Castro no había estado legítimamente casada con Pedro I, a pesar de lo que este había querido hacer creer. Además, todos habían sido traidores: Beatriz por seguir al papa cismático de Aviñón y los hermanos Castro por entrar armados en Portugal al servicio de Castilla. En consecuencia, el trono estaba vacante y competía a las Cortes conferirlo. Dada la urgencia, los tres estados eligieron rey a João, que tenía dignidad bastante para eso -era también hijo de rey, aunque natural-y lo merecía por haber defendido el reino de sus enemigos. Después de algunas dudas, el maestre de Avis aceptó la elección y se transformó en João I de Portugal ${ }^{88}$.

Durante la Edad Media, existían dos corrientes principales de pensamiento sobre el poder regio: en ambas, Dios era el origen de ese poder pero una, de tipo "descendente", sostenía que el mismo se transmitía de Dios al soberano, directamente o por intermediación de su representante en la tierra, el papa; la otra, de tipo "ascendente", proponía al pueblo como intermediario de la transmisión ${ }^{89}$. La monarquía portuguesa, tal como las otras monarquías ibéricas herederas de la visigótica, era una monarquía electiva (o sea, de tipo ascendente) en la que, sin embargo, se había ido consolidando con el tiempo el principio de la transmisión de la corona por sucesión hereditaria y primogenitura de varón ${ }^{90}$. Las cortes de 1385 invocaron, por lo tanto, el derecho a elegir a su soberano, inscrito en la constitución monárquica, después de demostrar que la sucesión hereditaria era imposible.

En 1438 no había ruptura de la sucesión hereditaria; lo que los representantes de los concejos querían era nombrar a otro regente, como sus antepasados en el cargo habían hecho con el maestre de Avis, pero la reina tenía importantes apoyos entre la nobleza y el clero $^{91}$. La única cosa que el

${ }^{86}$ Lopes 1973, cap. CLIV, p. 285.

${ }^{87}$ Y que Fernão Lopes reconstituye en su crónica a partir del auto de elección del rey, como demostró Caetano 1985b, pp. 18-36.

${ }^{88} \mathrm{El}$ auto de elección de João I está publicado en ibidem, doc. 1, pp. 91-101.

${ }^{89}$ Ullmann 1978, pp. 20-21.

90 Rebelo 1983, pp. 39-40.

${ }^{91}$ Pina refiere al mariscal del reino, al arzobispo de Lisboa, al prior de Crato y a "casi todos los hidalgos del reino", Pina 1977, cap. X, p. 597. 
infante Henrique logró, haciendo de intermediario entre los diferentes partidos presentes en las cortes, fue llegar a un acuerdo en que la regencia sería repartida: Leonor de Aragón mantendría la tutela de sus hijos y la gestión de la hacienda, Pedro se ocuparía de la defensa del reino y el conde de Arraio$\operatorname{los}^{92}$ de la justicia. La reina no quiso aceptarlo en un primero momento pero, ante el alboroto ${ }^{93}$ provocado por los populares, que se afirmaban dispuestos a entregar a Pedro toda la regencia, se sometió ${ }^{94}$.

Durante varios meses, Leonor de Aragón y Pedro gobernaron conjuntamente ${ }^{95}$ pero con creciente impaciencia por parte del infante, que quería regir solo y no cesó de recibir demonstraciones de apoyo de sus partidarios nobles y populares. Por otro lado, algunas de las medidas tomadas por la reina suscitaron la reprobación de los hombres buenos y del pueblo menudo de Lisboa, que siguió alborotándose y haciendo uniones en contra de ella y de sus partidarios. En los acontecimientos relatados por Rui de Pina a partir de agosto de 1439, encontramos ecos del ambiente revolucionario de medio siglo atrás: un oficial de la reina fue defenestrado; se lanzaron amenazas de destruir y quemar un convento en lo que se había refugiado un fraile de su confianza; la intervención del conde de Arraiolos, titular de la justicia, no restauró la paz y solo el infante Pedro logró aquietar a los revoltosos. Tal como Leonor Teles, Leonor de Aragón dejó de sentirse segura en Lisboa y se retiró para su villa de Alenquer ${ }^{96}$. En su ausencia, siguieron los ataques a sus partidarios ${ }^{97}$, el castillo, en manos de uno de ellos, fue tomado y los hidalgos, ciudadanos y hombres buenos de la ciudad eligieron regidor del reino a Pedro, que aceptó la elección antes de la reunión de las cortes ${ }^{98}$. Esto valió al infante una acusación de tiranía algunos años más tarde ${ }^{99}$.

${ }^{92}$ Hijo de Afonso, conde de Barcelos, a su vez hijo natural de João I. Afonso y sus dos hijos, los condes de Arraiolos y Ourém, miembros muy activos y escuchados del concejo real en los reinados de João I y Duarte, seguían inmediatamente a los infantes Pedro, Henrique y João en la jerarquía de la nobleza portuguesa.

${ }^{93}$ El término "alvoroço" (alboroto), aquí utilizado por Pina, es el mismo que Lopes utiliza para referirse a los sucesivos movimientos populares en contra la regente Leonor Teles y sus partidarios.

${ }^{94}$ Pina 1977 , cap. XV, pp. 602-603.

${ }^{95}$ Los documentos expedidos por los dos que aún se encuentran en los registros de la cancillería de Afonso V son referidos por Moreno 1979, pp. 25-29.

${ }^{96}$ Pina 1977, caps. XIX-XXXI, pp. 607-621.

${ }^{97}$ Relata un monje de Alcobaça que "un día derribaron a las casas del arzobispo de Lisboa y si lo hubieron encontrado lo hubieron matado", ANTT, Mosteiro de Alcobaça, L. 14, ff. 361 v$362 \mathrm{v}$, publicado por Rau 1964, pp. 149-150.

${ }_{98}$ Pina 1977, caps. XXXII-XLI, pp. 622-632.

${ }^{99}$ Gomes 2012. 


\section{DE NUEVO EL ARGUMENTO DEL GÉNERO}

En las nuevas cortes reunidas en Lisboa en diciembre de 1439, los tres estados votaron favorablemente una propuesta del doctor Diogo Afonso Mangancha -el artífice de la elección popular- para que Pedro fuese investido de la regencia in solidum. Rui de Pina nos dice que ese jurista:

enseñó con claras razones, aprobadas por Derecho Divino y Humano, y autorizadas por claros ejemplos, que Mujer no debe tener Regimiento. Ni que dos en compañía no deben regir; pero uno solo, y para ser uno solo debía ser el infante don Pedro ${ }^{100}$.

Desgraciadamente, como el cronista no transmite su discurso y no quedó registro de él, no sabemos qué claras razones fueron esas, pero no queda duda de que fue, de nuevo, invocado el argumento de la ineptitud del género femenino para el gobierno. La reina se opuso a esa decisión y rechazó llevar a su hijo a Lisboa para que protagonizara el cambio de régimen, pero al final se dejó convencer por el infante Henrique y se hizo la ceremonia apropiada: delante de los tres estados, el rey entregó a su tío Pedro, arrodillado ante sus pies, un bastón con su sello en señal y nombre de Poderío, volviendo legal la usurpación cometida ${ }^{101}$. Hay quién sostenga que fueron la amenidad de la reina, su benignidad e indolencia en lugar de la fuerza que le era exigida para alejar el cuñado y asumir en pleno las atribuciones de gobernante las que hicieron de ella una regidora incompetente a los ojos de sus contemporáneos y dictaron su destitución ${ }^{102}$.

Pero Leonor no solo fue destituída de la regencia. Cuando las cortes llegaban a su fin, los representantes de los concejos propusieron que se le retirara la tutoría de sus dos hijos varones porque la criación del rey, por ser en poder de mujeres, le es muy dañosa, y siempre por eso quedará débil y afeminado, mientras el infante Pedro:

lo criaría, y haría enseñar en letras, y Reales costumbres, y lo llevaría al monte y a la caza, y le enseñaría por él mismo el ejercicio de las armas, y por ejemplos y doctrina, los merecimientos de la caballería. Y así las otras ceremonias, mañas, y cosas que al Estado de un tal Príncipe convienen ${ }^{103}$.

${ }^{100}$ Pina 1977, cap. XLVI, pp. 638-639.

${ }^{101}$ Ibidem, cap. XLIX, p. 642.

${ }^{102}$ Freitas 2004, p. 84.

103 Pina 1977, cap. L, pp. 643-645. 
Estos argumentos son muy curiosos en la medida en que en otros reinos, como el de Francia, se consideraba que las mujeres eran naturalmente incapaces de gobernar pero que las madres eran las que naturalmente mejor sabían ocuparse de sus hijos y de los intereses respectivos; eso llevó a que se confiara preferentemente a las reinas madres la tutoría de sus hijos e incluso la regencia del reino ${ }^{104}$. En este caso, todavía, se afirmaba que dejar al niño al cuidado de la madre le produciría un daño, una mutilación de su virilidad ${ }^{105}$. Es verdad que Afonso V ya había cumplido siete años, edad en la que era habitual que los niños dejaran a sus madres, junto a las cuales habían sido educados hasta entonces, para integrarse en un ambiente masculino ${ }^{106}$. Sin embargo, su padre lo había dotado de un ayo ${ }^{107}$ para enseñarle las artes y mañas de la caballería, y era poco probable que Pedro tuviese tiempo para ocuparse de su educación intelectual y física en medio a los pesados quehaceres de la regencia. En realidad, las otras razones presentadas por los procuradores para alejar al pequeño rey de su madre nos parecen más pertinentes: porque, caso contrario, ella lo criaría en el odio al tío y a todos los que la habían privado del poder, y se gastarían más recursos ${ }^{108}$.

La propuesta fue aprobada por las cortes. Pedro, sin embargo, manifestó su renuencia a aceptar el encargo y, ante la insistencia de los procuradores, propuso quedarse con la tutela de los niños con condición que la reina los acompañara siempre por el reino, para poder seguir criando a sus hijos. Seguramente, el infante sabía que retirarle a una madre la custodia de sus hijos, que le había sido confiada por su marido difunto en testamento era, además de una crueldad, un acto ilegal ${ }^{109}$. Una ley de João I había determinado que:

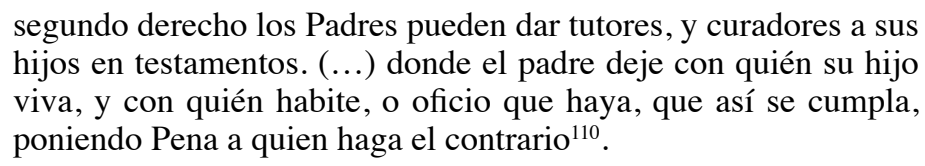

Y, antes de esta, una ley del siglo XII preveía que, muerto el padre, si la madre no volviese a casar tendría la guarda de los hijos y de sus bienes

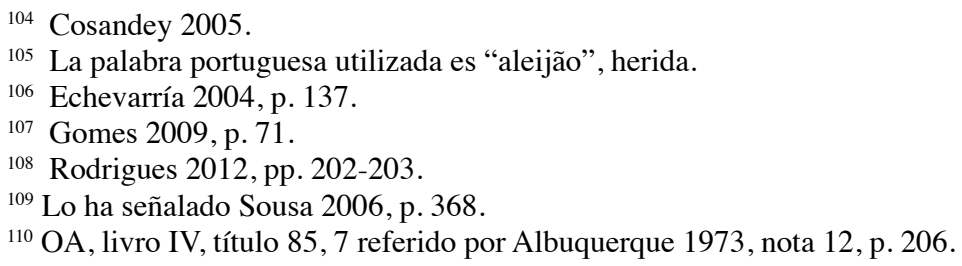


hasta que fueran mayores de edad ${ }^{111}$. Es verdad que el soberano no era un padre cualquiera, pero en ausencia de una norma que le fuera propia tenía que someterse a la ley común; cuando una ley pública fue promulgada, en 1674, el principio se mantuvo: se confirió al rey poder para nombrar, en su testamento, tutor o tutores para su sucesor menor de catorce años de edad ${ }^{112}$. Pedro intentó, por lo tanto, obtener más ascendencia sobre el rey y contentar a sus partidarios sin provocar una ruptura total con la reina. Leonor, sin embargo, declaró que solo aceptaría la tutela plena de todos sus hijos, asociada además a la gestión de la hacienda, como había sido decretado en las cortes del año anterior. Como no le fue concedido, prefirió separarse de Afonso V y Fernando e irse para sus tierras con sus hijas y la gente de su casa, en un intento de escapar al control de Pedro para preparar mejor su regreso al poder ${ }^{113}$.

\section{DE NUEVO EL ARGUMENTO NACIONALISTA}

Ya hemos visto que, desde el inicio de su regencia, uno de los argumentos esgrimidos contra Leonor de Aragón fue su origen extranjero ${ }^{114}$ : lo que había sido una ventaja en el momento de su boda -garantizar una alianza con el reino de Aragón contra el de Castilla- se había vuelto un inconveniente después de alcanzada la paz con Castilla en 1431, porque sus hermanos no cesaban de causar perturbaciones en ese reino ${ }^{115}$. A partir de septiembre de 1439, Pedro acusó públicamente a Leonor de apelar a los infantes de Aragón para que viniesen armados a Portugal a defender su estado, lo que causó enorme conmoción popular y favoreció su destitución. Sobre las cartas enviadas por él a las ciudades y villas portuguesas sobre este tema dice Pina:

si el infante esto escribió por tener de esto, en ese tiempo, alguna seguridad, o si lo hizo a propósito para alborotar las gentes contra la Reina, y contra los que seguían su intención, quede con Dios y su consciencia ${ }^{116}$.

No hay ninguna duda, sin embargo, que después de su destitución Leonor envió mensajes a sus hermanos y a su primo Juan II para que interp. 217.

${ }^{111}$ PMH, Leges et Consuetudines, vol. 1, núm. XV referido por Albuquerque 1973, nota 56,

${ }_{112}$ Albuquerque 1973, p. 213.

${ }^{113}$ Pina 1977, caps. L-LI, pp. 643-648.

${ }^{114}$ Véase la nota 78.

${ }^{115}$ Sobre los denominados “infantes de Aragón”, véase Benito Ruano 2002.

${ }^{116}$ Pina 1977, cap. XXIX, p. 619. 
vinieran en su favor. Los reyes de Aragón y de Castilla enviaron embajadas a Portugal para exigir que fuese restituida a la reina la tutoría de sus hijos y la regencia, bajo amenazas de guerra ${ }^{117}$; esto exacerbó aun más la oposición a Leonor. Pedro preparó el reino para la guerra, pero también buscó una solución política, aliándose al condestable de Castilla Álvaro de Luna, que intentaba recuperar el control del rey castellano, perdido para sus rivales ${ }^{118}$.

En noviembre de 1440, Leonor se dirigió a la frontera en un intento de reunirse con sus partidarios portugueses haciendo un breve giro por Castilla, porque el regente le impedía el paso por el territorio portugués. Pero sus planes fallaron y, en diciembre, tuvo que refugiarse en el reino vecino ${ }^{119}$. Fue un exilio definitivo. A partir de entonces, en la corte castellana, no cesó de ayudar política y económicamente a sus hermanos en su pugna con Álvaro de Luna para que mantuviesen su influencia sobre Juan II y pudiesen presionarlo a exigir su regreso a Portugal y a la regencia ${ }^{120}$. Inversamente, Pedro no cesó de apoyar a Álvaro de Luna en su lucha contra los infantes de Aragón, incluso militarmente: conocemos nada menos que tres expediciones militares enviadas por él a Castilla, la última de las cuales llegó después de la derrota de los infantes en Olmedo y no tuvo que intervenir ${ }^{121}$. La muerte de Leonor de Aragón en Toledo, en febrero de 1445, puso fin al conflicto por la regencia ${ }^{122}$, pero la alianza entre el infante Pedro y el condestable de Castilla permaneció viva y vigente hasta la caída en desgracia y la muerte de ambos, algunos años más tarde.

\section{CONCLUSIÓN}

En ausencia de una ley sobre la sucesión al trono, era la costumbre de la monarquía portuguesa la que permitía a las hijas suceder a sus padres cuando no había un heredero masculino, y a las reinas madres ejercer la regencia en nombre de sus hijos menores de edad, al igual de lo que sucedía en León, Castilla y Navarra. No fue por ser una hembra que Beatriz fue destituida de la corona, pero sí por ser considerada ilegítima y cismática, y a Leonor

${ }^{117}$ Ibidem, caps. LIII, LXII, LXIX, pp. 649-650, 661-663, 669-670. 1998.

${ }^{118}$ Sobre este personaje y su larga pugna con los infantes de Aragón, véase Calderón Ortega

${ }^{119}$ Pina 1977, caps. LIX, LXIII-LXXXIV, pp. 659, 663-677.

${ }^{120}$ Rodrigues 2012, pp. 217-221.

${ }^{121}$ Ibidem, pp. 221-236, 246-247.

${ }^{122}$ Las crónicas sugieren que, como su hermana María, fallecida por la misma época, Leonor fue envenenada a mando del infante Pedro o de Álvaro de Luna. Recientemente, se sugirió que sucumbieron ambas a la meningitis, Álvarez Palenzuela 2006, p. 370. 
Teles no le acusaron jamás de debilidad femenina en la conducción de los negocios del reino. Lo que no quiere decir que no existiera un perjuicio en contra del ejercicio del poder por las mujeres, que podía o no ser expresado abiertamente según lo que más convenía en cada momento. En el caso de Leonor de Aragón, su género fue efectivamente uno de los argumentos utilizados para descalificarla como regente e incluso como educadora del rey niño. Pero eso no supuso un cambio definitivo de orientación: cuando, un siglo más tarde, ocurrió una nueva minoría de edad del heredero del trono a la muerte de João III (1521-1557), fue su viuda, la reina Catarina de Austria, la escogida para regir en nombre de su nieto Sebastião $(1557-1578)^{123}$.

Portugal tampoco se distinguió del panorama ibérico, e incluso transpirenaico, en cuanto a la importancia que los tíos paternos de los reyes niños tuvieron en la oposición a la regencia de las reinas madres y la usurpación del trono de sus sobrinos ${ }^{124}$. En 1383, el infante João de Castro no pudo presentarse como una alternativa al gobierno de Leonor Teles porque estaba exiliado en Castilla y Juan I lo prendió apenas supo que Fernando I había muerto, anticipando posibles problemas. Sin embargo, para encabezar su lucha los revoltosos buscaron a otro hermanastro del rey difunto, el maestre de Avis, que no solo creó un gobierno paralelo al de la regente como acabó haciéndose elegir rey. A partir de 1438, la oposición a Leonor de Aragón también se organizó en torno a los hermanos -legítimos esta vez-del monarca fallecido, el mayor de los cuales logró arrebatarle la regencia y forzarla al exilio.

Lo que sí parece constituir la singularidad portuguesa en este ámbito es el protagonismo del elemento burgués y popular en los movimientos que impusieron los cambios en las regencias. En 1383 como en 1439, si es de creer lo que relatan los cronistas, fue el pueblo menudo de Lisboa el que se alborotó contra las regentes y escogió para sustituirlas dos hermanos de los reyes difuntos, forzando los hombres buenos del concejo a confirmar la elección; sólo en un segundo momento fue esta decisión ratificada por las cortes, ganando un peso legal. En ambas ocasiones, los tres estados fueron convencidos por discursos hechos por juristas laicos oriundos también del estamento popular. Las cortes de 1385 llevaron además su legitimidad institucional hasta decretar el trono vacante y elegir un nuevo rey, dando inicio a una nueva dinastía. Las de 1439 se limitaron a cambiar el regente. Las dos, sin embargo, marcan el triunfo en Portugal del principio por el que el poder se transmitía a través del pueblo, que sabía reconocer las señales con las que Dios ornaba a los electos ${ }^{125}$.

\footnotetext{
${ }^{123}$ El padre del niño había fallecido tres años antes y la madre, Juana de Austria, había sido llamada por Carlos V a gobernar Castilla, Cruz 1992.

${ }^{124}$ Corvisier 2002, p. 114.

${ }^{125}$ Sobre el maestre de Avis como un electo por Dios, véase Ventura 1992.
} 
$\mathrm{Al}$ rodearse sobre todo de nobles y clérigos, algunos de ellos extranjeros, y de hombres de otra fe, las dos regentes alejaron de su partido a los burgueses y al pueblo llano, que sus rivales supieron atraer y movilizar, provocando así su destitución.

\section{BIBLIOGRAFÍA CITADA}

Albuquerque, Martim de (1973), As regências na história do direito público e das ideias políticas em Portugal, separata de Portugaliae Historicae, vol. I, Lisboa.

Albuquerque, Martim de (1974), A consciência nacional portuguesa. Ensaio de história das ideias políticas, Lisboa, Faculdade de Letras da Universidade de Lisboa.

Álvarez Palenzuela, Vicente Ángel (2006), María, infanta de Aragón y reina de Castilla, en Estudos em homenagem ao Professor Doutor José Marques, Oporto, Faculdade de Letras da Universidade do Porto, vol. IV, pp. 349-370.

Almeida, M. Lopes de (1977), Introdução, en Crónicas de Rui de Pina, Oporto, Lello \& Irmão, pp. V-XXIII.

Alves, Horácio Ferreira (1927), Dois caluniados (D. Fernando e Leonor Teles), Lisboa, Livraria Clássica Editora.

Amado, Teresa (1991), Fernão Lopes contador de História. Sobre a Crónica de D. João I, Lisboa, Estampa.

Amado, Teresa (2007), Projecto histórico de um infante, en Eadem, O passado e o presente: ler Fernão Lopes, Lisboa, Presença, pp. 140-151.

Arnaut, Salvador Dias (1960), A crise nacional dos fins do século XIV, I: a sucessão de D. Fernando, Coímbra, Faculdade de Letras da Universidade de Coimbra.

Ayala, Pedro López de (1877), Crónica del Rey Don Juan, primero de Castilla é de Leon, en Rosell, Cayetano, Crónicas de los Reyes de Castilla, Madrid, Rivadeneyra, t. II, pp. 5-144.

Baleiras, Isabel de Pina (2012), Uma rainha inesperada. Leonor Teles, Lisboa, Círculo de Leitores.

Baleiras, Isabel de Pina (2013), The Political Role of a Portuguese Queen in the Late Fourteenth Century, en Woodacre, Elena (ed.), Queenship in the Mediterranean. Negotiating the Role of the Queen in the Medieval and Early Modern Eras, Nueva York, Palgrave Macmillan, pp. 97-123.

Baptista, Júlio César (1956), Portugal e o Cisma do Ocidente, "Lusitania Sacra" 1, pp. 65-203. 
Benito Ruano, Eloy (2002), Los Infantes de Aragón, Madrid, Real Academia de la Historia (1a ed.: 1952).

Biachini, Janna (2012), The Queen's Hand. Power and Authority in the Reign of Berenguela of Castile, Filadelfia, Penn Press.

Calado, Adelino de Almeida (ed.) (1998), Crónica de Portugal de 1419, Aveiro, Universidade de Aveiro.

Calderón Ortega, José Manuel (1998), Álvaro de Luna: riqueza y poder en la Castilla del siglo $X V$, Madrid, Dykinson.

Caetano, Marcelo (1985a), O concelho de Lisboa na crise de 1383-1385, en Idem, A crise nacional de 1383-1385. Subsídios para o seu estudo, Lisboa - São Paulo, Verbo, pp. 123-207.

Caetano, Marcelo (1985b), As cortes de 1385, en Idem, A crise nacional de 1383-1385. Subsídios para o seu estudo, Lisboa - São Paulo, Verbo, pp. 7-122.

Carmona Ruiz, María Antonia (2005), María de Molina, Barcelona, Plaza Janés.

Carvalho-Gonçalves, Leonardo (2014), Culte funéraire royal dans le Portugal des dynasties d'Avis et de Habsbourg, París, Université de Paris IPanthéon-Sorbonne (tesis de Master).

Coelho, Maria Helena da Cruz (2008), D. João I, Lisboa, Temas e Debates.

Collins, Roger (1993), Queens-Dowager and Queens-Regent in Tenth-Century León and Navarre, en Parsons, John Carmi (ed.), Medieval Queenship, Nueva York, St. Martin's Press, pp. 79-92.

Corvisier, André (2002), Les régences en Europe, París, Presses Universitaires de France.

Cosandey, Fanny (2005), Puissance maternelle et pouvoir politique: la régence des reines mères, "Clio, Histoire, Femmes et Sociétés" 21, pp. 69-90.

Costa, João Paulo Oliveira e (2009), Henrique o Infante, Lisboa, Esfera dos Livros.

Costa, António Domingues de Sousa (1982), Monumenta Portugaliae Vaticana, vol. III-1, Braga - Oporto, Editorial Franciscana.

Cruz, Maria do Rosário de Sampaio Themudo Barata de Azevedo (1992), As regências na menoridade de D. Sebastião. Elementos para uma história estrutural, vol. I, Lisboa, Imprensa Nacional-Casa da Moeda.

Duarte, Luís Miguel (2007), D. Duarte, Lisboa, Temas e Debates.

Duarte, Manuel Marques (2002), Leonor Teles, Oporto, Campo das Letras.

Earenfight, Theresa (2010), The King's Other Body. María of Castile and the Crown of Aragón, Filadelfia, Penn Press.

Echevarría, Ana (2002), Catalina de Lancaster. Reina regente de Castilla (1372-1418), Hondarribia, Nerea. 
Ferreira, Maria Emília Cordeiro (1975), Pina, Rui de (1440?-1522), en Serrão, Joel (dir.), Dicionário de História de Portugal, ed. especial, Oporto, Livraria Figueirinhas, vol. V, pp. 81-83.

Fontes, João Luís Inglês (2000), Percursos e memória. Do infante D. Fernando ao Infante Santo, Cascais, Patrimonia.

Freire, Anselmo Braamcamp (1973), Introdução, en Lopes, Fernão, Crónica de D. João I, ed. fac-similada da ed. Anselmo Braamcamp Freire e William Entwistle, Lisboa, Imprensa Nacional-Casa da Moeda, vol. I, pp. V-LXX.

Freitas, Judite A. Gonçalves de (2004), D. Leonor de Aragão: imagens de contestação e de poder, en Toscano, Ana Maria da Costa; Godsland, Shelley (eds.), Mulheres Más. Percepção e representações da mulher transgressora no mundo luso-hispânico, Lisboa, Edições Universidade Fernando Pessoa, vol. I, pp. 73-86.

Freitas, Judite A. Gonçalves de (2012), O Estado em Portugal (séculos XII$X V)$, Lisboa, Alétheia.

Godinho, Vitorino Magalhães (2004), Portugal. A emergência de uma nação (das raízes a 1480), Lisboa, Colibri - FCSH da Universidade Nova de Lisboa.

Gomes, Rita Costa (1995), A corte dos reis de Portugal no final da Idade Média, Lisboa, Difel.

Gomes, Rita Costa (2005), D. Fernando, Lisboa, Círculo de Leitores.

Gomes, Rita Costa (2012), Alfarrobeira: The Death of the Tyrant?, en Spiess, Karl-Heinz; Warntjes, Immo (eds.), Death at Court, Wiesbaden, Harrassovitz Verlag, pp. 135-158.

Gomes, Saul António (2009), D. Afonso V, Lisboa, Temas e Debates.

Homem, Armando Luís de Carvalho (1990), O Desembargo Régio (13201433), Oporto, INIC.

Hutchinson, Amelia (2005), Punctuating the Narrative: The Structural Function of Female Characters in Fernão Lopes' and Gomes Eanes de Zurara's Chronicles, "Portuguese Studies Review" 13/1-2, pp. 1-14.

Lopes, Fernão (1966), Crónica de D. Pedro I, ed. Giuliano Macchi, Roma, Atheneo.

Lopes, Fernão (1973), Crónica de D. João I, ed. fac-similada da ed. Anselmo Braamcamp Freire e William Entwistle, vol. I, Lisboa, Imprensa Nacional-Casa da Moeda.

Lopes, Fernão (2004), Crónica de D. Fernando, ed. Giuliano Macchi, Lisboa, Imprensa Nacional-Casa da Moeda.

Marques, A.H. de Oliveira (1974), Introdução, en Idem, Antologia da Historiografia Portuguesa, vol. 1, Das origens a Herculano, Lisboa, Europa-América, pp. 7-52. 
Marques, A.H. de Oliveira (1975), Lopes, Fernão (séc. XIV-séc. XV), en Serrão, Joel (dir.), Dicionário de História de Portugal, ed. especial, Oporto, Livraria Figueirinhas, vol. IV, pp. 56-58.

Marques, A.H. de Oliveira (dir.) (1990), Cortes Portuguesas. Reinado de D. Fernando I (1367-1383), vol. I, Lisboa, INIC.

Marques, José (1989), Clérigos portugueses exilados e beneficiados em Castela Nova e Andaluzia nos finais do século XIV, "Revista de Ciências Históricas" 4, pp. 177-194.

Marques, Maria Alegria Fernandes (2013), O papel das rainhas viúvas na consolidação do reino (Os testamentos dos primeiros reis de Portugal), "Revista Portuguesa de História" 44, pp. 79-93.

Mattoso, José (1985a), A nobreza e a revolução de 1383, en 1383/1385e a crise geral dos séculos XIV e XV. Jornadas de História Medieval, Lisboa, História \& Crítica, pp. 391-402.

Mattoso, José (1985b), O essencial sobre a formação da nacionalidade, Lisboa, Imprensa Nacional-Casa da Moeda.

Medeiros, Maria Dulcina Vieira Coelho de (1999), O infante D. João: 1400-1442: subsídios para uma biografia, Lisboa, Faculdade de Letras da Universidade de Lisboa (tesis de Master).

Monteiro, João Gouveia (1988), Fernão Lopes. Texto e contexto, Coímbra, Minerva.

Moreira, Filipe Alves (2013), A Crónica de Portugal de 1419. Fontes, estratégias e posteridade, Lisboa, Fundação Calouste Gulbenkian.

Moreno, Humberto Baquero (1979), A batalha de Alfarrobeira. Antecedentes e significado histórico, vol. I, Coímbra, Por ordem da Universidade (2a edición).

Moreno, Humberto Baquero (1997), O infante D. Pedro, duque de Coimbra. Itinerários e ensaios históricos, Oporto, Universidade Portucalense.

Moreno, Humberto Baquero (2009), Dona Leonor de Teles: uma mulher sedutora e inquieta, en Estudos em Memória do Professor Doutor Mário de Albuquerque, Lisboa, Faculdade de Letras da Universidade de Lisboa, pp. 419-438.

Oliveira, Ana Rodrigues (2010), Leonor Teles (c. 1350- c. 1405). A rainha de má memória, en Eadem, Rainhas Medievais de Portugal, Lisboa, A esfera dos livros, pp. 305-364.

Olivera Serrano, César (2005), Beatriz de Portugal. La pugna dinástica Avís-Trastámara, Santiago de Compostela, Cuadernos de Estudios Gallegos.

Pina, Rui de (1977), Chronica do Senhor Rey D. Affonso V, en Lopes de Almeida, Manuel (ed.), Crónicas de Rui de Pina, Oporto, Lello \& Irmão, pp. 577-881. 
Rau, Virgínia (1964), O infante D. Pedro e a regência do reino em 1439, "Revista da Faculdade de Letras de Lisboa" 3a série 8, pp. 143-150

Rebelo, Luís de Sousa (1983), A concepção do poder em Fernão Lopes, Lisboa, Livros Horizonte.

Rodrigues, Ana Maria S.A. (2012), As tristes rainhas: Leonor de Aragão, Isabel de Coimbra, Lisboa, Círculo de Leitores.

Rodrigues, Ana Maria S.A.; Vilar, Hermínia Vasconcelos (2003), Os cónegos à escala da Cristandade: o caso português, en Fonseca, Luís Adão da; Amaral, Luís Carlos; Santos, Maria Fernanda Ferreira (coords.), Os reinos ibéricos na Idade Média. Livro de Homenagem ao Professor Doutor Humberto Carlos Baquero Moreno, Oporto, Livraria Civilização, vol. I, pp. 141-152.

Russel, Peter (2004), Henrique o Navegador, Lisboa, Livros Horizonte.

Russel, Peter Edward (1938), João Fernandes Andeiro at the court of John of Lancaster, 1371-1381, Coímbra, Imprensa Académica.

Russel, Peter Edward (1941), As fontes de Fernão Lopes, Coímbra, Coimbra Editora.

Shadis, Miriam (2009), Berenguela of Castile (1180-1246) and Political Women of the High Middle Ages, Nueva York, Palgrave Macmillan.

Silva, Manuela Santos (2014), A construção coeva da imagem de Filipa de Lencastre como uma "santa rainha", en Vilela, Ana Luísa; Esteves, Elisa Nunes; Silva, Fabio Mário da; Reffóios, Margarida (dirs.), Representações do Mito na História e na Literatura, Évora, Universidade de Évora, pp. 137-149.

Sousa, Ana Paula (2004), Leonor Teles: "Huuma maa moolher"?, Oporto, Faculdade de Letras da Universidade do Porto (tesis de Master).

Sousa, Armindo de (1984), A morte de D. João I (Um tema de propaganda dinástica), "Lucerna" número extraordinário, pp. 417-481.

Sousa, Armindo (1993), 1325-1480, en A monarquia feudal, en Mattoso, José (dir.), História de Portugal, Lisboa, Círculo de Leitores, vol. 2, pp. 313-556.

Sousa, João Silva de (2006), D. Leonor, a triste rainha, en Estudos em homenagem ao Professor Doutor José Marques, Oporto, Faculdade de Letras da Universidade do Porto, vol. 2, pp. 359-373.

Tavares, Maria José Ferro (2013), Fernando e Leonor. Um reinado (mal)dito, Lisboa, Chiado Editora.

Tavares, Maria José Pimenta Ferro (1983), A nobreza no reinado de D. Fernando e a sua actuação em 1383-1385, "Revista de História Económica e Social" 12, pp. 45-89.

Ullman, Walter (1978), Principles of Government and Politics in the Middle Ages, Londres, Methuen \&Co (1a edición: 1961; 3a edición). 
Valdeón Baruque, Julio (2002), Los Trastámaras. El triunfo de una dinastía bastarda, Madrid, Temas de Hoy (1a edición: 2001; 3a edición).

Ventura, Margarida Garcez (1992), O Messias de Lisboa -um estudo de mitologia política (1385-1415), Lisboa, Cosmos.

Viegas, Valentino (1985), Lisboa a força da revolução (1383-1385). Os documentos comprovam Fernão Lopes, Lisboa, Livros Horizonte.

Wiswall III, Frank L. (1997), Politics, procedure and the "non-minority" of Edward III: some comparisons, en Gillespie, James L. (ed.), The Age of Richard II, Stroud, Sutton Publishing, pp. 7-25.

Zurara, Gomes Eanes de (1978), Crónica do conde D. Duarte de Meneses, ed. Larry King, Lisboa, Universidade Nova de Lisboa.

Zurara, Gomes Eanes de (1992), Crónica da Tomada de Ceuta, Introdução e Notas de Reis Brasil, Lisboa, Publicações Europa-América.

Fecha de recepción del artículo: mayo 2015

Fecha de aceptación y versión final: enero 2016 